\title{
Influence of Microwave Incinerated Rice Husk Ash on Hydration of Foamed Concrete
}

\author{
R. Bayuaji ${ }^{1}$ and M. F. Nuruddin ${ }^{2}$ \\ ${ }^{1}$ Institut Teknologi Sepuluh Nopember, Civil Engineering Department, Sukolilo, Surabaya, Indonesia \\ ${ }^{2}$ Civil Engineering Department, Universiti Teknologi Petronas, 31750 Tronoh, Perak, Malaysia \\ Correspondence should be addressed to R. Bayuaji; bayuaji@ce.its.ac.id
}

Received 1 April 2014; Revised 9 July 2014; Accepted 24 July 2014; Published 14 August 2014

Academic Editor: Serji N. Amirkhanian

Copyright (c) 2014 R. Bayuaji and M. F. Nuruddin. This is an open access article distributed under the Creative Commons Attribution License, which permits unrestricted use, distribution, and reproduction in any medium, provided the original work is properly cited.

\begin{abstract}
This research explains the results of an investigation carried out to understand the influence of a microwave incinerated rice husk ash (MIRHA) powder on foamed concrete (FC) hydration. The experimental work was designed using the Taguchi approach. This method was selected to have a target for the optimum working conditions of the parameter that affects some physical properties of concrete mixtures. The loss on ignition (LOI) method was used to establish the nonevaporable water $\left(w_{n}\right)$ content at all selected ages of hydration. It was observed that the MIRHA powder showed lower nonevaporable water contents than the normal FC, indicating that MIRHA powder facilitated enhancement in FC hydration. The optimum FC properties were achieved at $10 \%$ MIRHA composition as proven from the highest compressive strength. This level corresponds to the highest values in change in nonevaporable water and degree of hydration.
\end{abstract}

\section{Introduction}

Rice husks are by-products of paddy milling industries that attract attention due to their environmental issues [1]. Large amounts of rice husks are being produced annually in Malaysia almost reaching 2.2 million tons and the total annual world production is about 710 million tons [2]. Rice husk has large dry volume due to its low bulk density $\left(90-150 \mathrm{~kg} / \mathrm{m}^{3}\right)$ and possesses rough and abrasive surfaces that are highly resistant to natural degradation. That is why disposal of rice husks has become a challenging problem [1]. Therefore, from the viewpoint of environmental issues, how to improve rice husk and how to recycle rice husk have become very important environmental protection subjects. In recent years, various researchers [3-5] have investigated the use of microwave incinerated rice husk ash (MIRHA) in construction materials. Improper burning of rice husk cannot extract maximum amount of amorphous silica; therefore a correct burning procedure is vital to obtain good quality RHA that can contribute to the strength development and durability of concrete. In order to increase the reactivity, MIRHA was ground and sieved to a specific particle size. It was obtained that the inclusion of MIRHA could significantly improve the compressive strength of hardened concrete [4] while reducing the workability of fresh concrete [5]. MIRHA had positive effect in interfacial transition zone (ITZ) between aggregate and cement paste [4]. MIRHA decreases in the total porosity [6] caused the change occurring in the pore size distribution as a result of using RHA which could react with the calcium hydroxide to form C-S-H gel [7]. Controlled incineration of MIRHA between $500^{\circ} \mathrm{C}$ and $800^{\circ} \mathrm{C}$ produces noncrystalline amorphous RHA [3-6, 8].

Foamed concrete (FC) was initially envisaged as a void filing and insulation material [9]; there have been renewed interest in its structural characteristic in view of its lighter weight, savings in material, and potential for large-scale utilization of wastes $[10,11]$. Varieties of waste materials with supplementary cementitious materials potential are available, and their use in FC becomes an increasingly attractive option if there are environmental issues related to their disposal. The use of MIRHA as cement replacement material (CRM) in FC research is very limited. Moreover, the expense of some 
CRMs such as silica fume and high reactivity metakaolin increases the overall material cost of FC. Therefore, the use of less expensive RHA is more desirable to decrease the overall production cost of FC. The use of replacement materials in portland cement has attracted much attention in recent years. In blended cements, the cement replacement material may take part in the hydration reactions and contribute to the hydration products [12]. The CRMs group reacts with the $\mathrm{CH}$ produced during the cement hydration, while the second has hydraulic characteristics, but its hydration needs activation, for example, by the presence of hydration products (e.g., $\mathrm{CH}$ ) or other additives.

Research that discusses the process of hydration in FC is also limited except that by Jones and McCarthy [13-15], who presented some data on the heat of hydration of fly ash on FC. There is no information on the influence of RHA on FC hydration process. A quantitative determination of the degree of hydration of FC and RHA will lead to a better understanding of the mechanism of strength development of RHA-FC. In this paper, an investigation is being carried out to understand the mechanisms of deterioration of MIRHA effect, water binder ratio, and sand cement ratio on the FC. The experimental work was designed using the Taguchi approach. This method was selected to have a target for the optimum working conditions of the parameter that affects some physical properties of FC mixtures. One of the advantages of Taguchi method over the conventional experimental design, in addition to keeping the experimental cost at the minimum level, is that it minimizes the variability around the investigated parameters when bringing the performance value to target value. Its other benefit is that the optimum working conditions determined from the laboratory scale can also be replicated in the real production environment. This paper focuses on influence of MIRHA on FC hydration, and its comparison to plain FC.

\section{Experimental Investigation}

2.1. Materials. The constituent materials used in the laboratory to produce FC comprised (i) portland cement (Ordinary Portland Cement (OPC) BSEN 197-1), (ii) natural sand, with $100 \%$ passing $425 \mathrm{~mm}$ sieve, (iii) MIRHA, with high reactive silica content and under controlled combustion of rice husk, (iv) free water, and (v) superplasticizer. The foam agent used for the production of the preformed foam by aerating palm oil based LCM, a ratio of 1:30 (by volume), was aerated to a density of $110 \mathrm{~kg} / \mathrm{m}^{3}$. The chemical properties of MIRHA and OPC used are listed in Table 1.

2.2. Design of Experiments. The selection of the control factors is the most important stage in the design of experiment. As many variables as possible should be included in the investigation, so that it would be possible to identify nonsignificant variables at the earliest opportunity. Taguchi developed a method as a process optimization technique during the 1950s [18]. Taguchi's approach provides the design
TABLE 1: Binder properties.

\begin{tabular}{lcc}
\hline Oxide composition & \multicolumn{2}{c}{ Weight } \\
\hline $\mathrm{Na}_{2} \mathrm{O}$ & MIRHA & OPC \\
$\mathrm{MgO}$ & 0.02 & 0.02 \\
$\mathrm{Al}_{2} \mathrm{O}_{3}$ & 0.63 & 1.43 \\
$\mathrm{SiO}_{2}$ & 0.75 & 2.84 \\
$\mathrm{P}_{2} \mathrm{O}_{5}$ & 90.75 & 20.44 \\
$\mathrm{~K}_{2} \mathrm{O}$ & 2.50 & 0.10 \\
$\mathrm{CaO}$ & 3.77 & 0.26 \\
$\mathrm{TiO}_{2}$ & 0.87 & 67.73 \\
$\mathrm{Fe}_{2} \mathrm{O}_{3}$ & 0.02 & 0.17 \\
$\mathrm{SO}_{3}$ & 0.28 & 4.64 \\
$\mathrm{MnO}$ & 0.33 & 2.20 \\
\hline
\end{tabular}

TABLE 2: Parameters and their variation levels.

\begin{tabular}{lccccc}
\hline Variable & unit & Level 1 & Level 2 & Level 3 & Level 4 \\
\hline MIRHA & $(\%)$ & 0 & 5 & 10 & 15 \\
$w / c$ & Ratio & 0.35 & 0.4 & 0.45 & 0.5 \\
$s / c$ & Ratio & 0.25 & 0.5 & 0.75 & 1 \\
SP & $(\%)$ & 1 & 1.5 & 2 & 2.5 \\
FC & $(\%)$ & 20 & 25 & 30 & 35 \\
\hline
\end{tabular}

engineer with systematic and efficient method for determining near optimum design parameters in the achievement of performance target and cost.

In this investigation, the following parameters are considered in the mix compositions:

(i) microwave incinerated rice husk ash contents (MIRHA),

(ii) water cementitious ratio $(w / c)$,

(iii) sand cementitious ratio $(s / c)$,

(iv) superplasticizer content (SP),

(v) foam content (FC).

Ten steps in a methodical approach are used to the use of Taguchi's parameter design methodology [19]. Figure 1 shows the detail procedure of Taguchi design methodology.

The significant difference between Taguchi's approach with classical methodology is in step 7 of Figure 1 where the orthogonal matrix is employed parameters and levels. Table 2 shows the details of the variables used in the experiment. It is noted that the parameters are at four levels. Only 16 experiments are needed to study the whole experimental parameters using the standard $\mathrm{L}_{16}\left(4^{5}\right)$ orthogonal arrays (Table 3).

In addition, MIRHA was used to replace Ordinary Portland Cement (OPC) at the rate of $5 \%, 10 \%$, and $15 \%$ by weight of OPC as binder.

2.3. Preparation of Sample. The mix proportions of binders are presented in Table 4 . The mixes are prepared at about $5.5 \mathrm{~min}$ with a rotating planetary mixer. The fine aggregate 


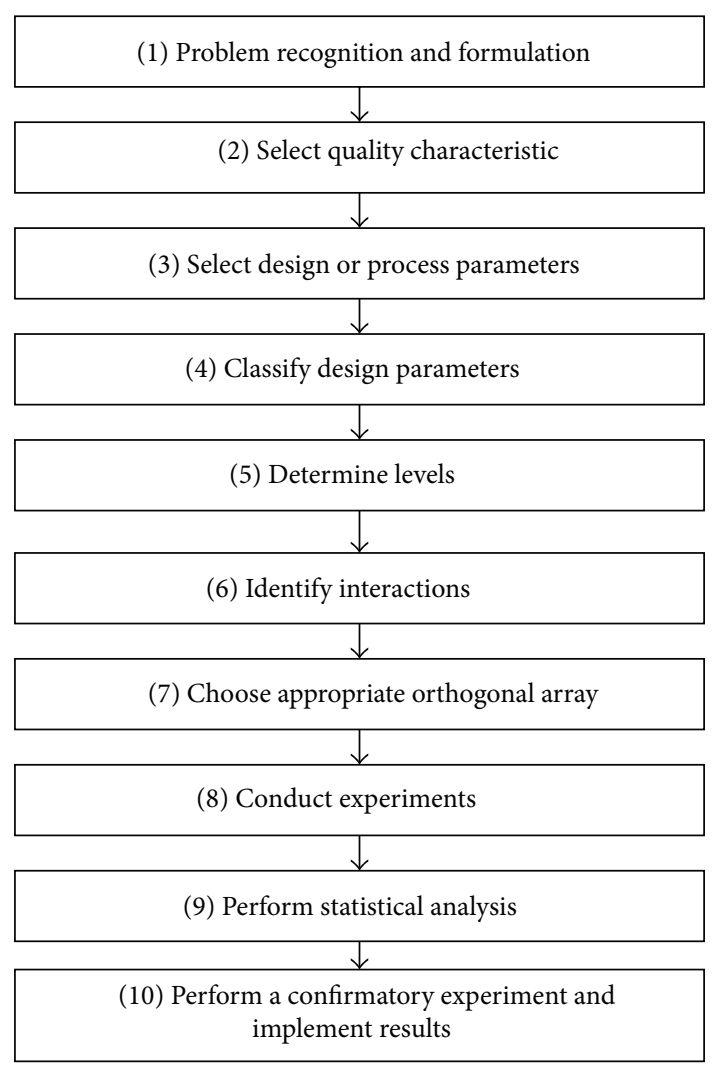

FIGURE 1: Taguchi method algorithm [16].

TABLE 3: Standard $\mathrm{L}_{16}$ orthogonal array.

\begin{tabular}{lcccccc}
\hline \multirow{2}{*}{ Exp. no. } & \multicolumn{5}{c}{ Independent variables } & Perform \\
& Var. 1 & Var. 2 & Var. 3 & Var. 4 & Var. 5 & parameter value \\
\hline 1 & 1 & 1 & 1 & 1 & 1 & FC-1 \\
2 & 1 & 2 & 2 & 2 & 2 & FC-2 \\
3 & 1 & 3 & 3 & 3 & 3 & FC-3 \\
4 & 1 & 4 & 4 & 4 & 4 & FC-4 \\
5 & 2 & 1 & 2 & 3 & 4 & FC-5 \\
6 & 2 & 2 & 1 & 4 & 3 & FC-6 \\
7 & 2 & 3 & 4 & 1 & 2 & FC-7 \\
8 & 2 & 4 & 3 & 2 & 1 & FC-8 \\
9 & 3 & 1 & 3 & 4 & 2 & FC-9 \\
10 & 3 & 2 & 4 & 3 & 1 & FC-10 \\
11 & 3 & 3 & 1 & 2 & 4 & FC-11 \\
12 & 3 & 4 & 2 & 1 & 3 & FC-12 \\
13 & 4 & 1 & 4 & 2 & 3 & FC-13 \\
14 & 4 & 2 & 3 & 1 & 4 & FC-14 \\
15 & 4 & 3 & 2 & 4 & 1 & FC-15 \\
16 & 4 & 4 & 1 & 3 & 2 & FC-16 \\
\hline
\end{tabular}

is first mixed with $1 / 2$ of water followed by the addition of PC and MIRHA. Afterwards, the rest of water and chemical admixtures are premixed and added to the mix. Finally, the appropriate volume of the foam is generated and added
TABLE 4: Mixture proportion of concrete.

\begin{tabular}{lcccccc}
\hline Code & $\begin{array}{c}\text { Cement } \\
\left(\mathrm{kg} / \mathrm{m}^{3}\right)\end{array}$ & $\begin{array}{c}\text { Sand } \\
\left(\mathrm{kg} / \mathrm{m}^{3}\right)\end{array}$ & $\begin{array}{c}\text { Water } \\
\left(\mathrm{kg} / \mathrm{m}^{3}\right)\end{array}$ & $\begin{array}{c}\text { MIRHA } \\
\left(\mathrm{kg} / \mathrm{m}^{3}\right)\end{array}$ & $\begin{array}{c}\text { Vol. of } \\
\text { foam } \\
(\text { liter/m }\end{array}$ & $\begin{array}{c}\mathrm{SP} \\
\left(\mathrm{kg} / \mathrm{m}^{3}\right)\end{array}$ \\
\hline FC-1 & 1050 & 263 & 368 & 0 & 200 & 0 \\
FC-2 & 828 & 414 & 331 & 0 & 250 & 4 \\
FC-3 & 666 & 500 & 300 & 0 & 300 & 7 \\
FC-4 & 544 & 544 & 272 & 0 & 350 & 8 \\
FC-5 & 779 & 195 & 312 & 39 & 350 & 8 \\
FC-6 & 797 & 398 & 279 & 40 & 300 & 12 \\
FC-7 & 668 & 501 & 334 & 33 & 250 & 0 \\
FC-8 & 685 & 685 & 308 & 34 & 200 & 3 \\
FC-9 & 827 & 207 & 372 & 83 & 250 & 12 \\
FC-10 & 761 & 381 & 381 & 76 & 200 & 8 \\
FC-11 & 653 & 490 & 229 & 65 & 350 & 3 \\
FC-12 & 614 & 614 & 246 & 61 & 300 & 0 \\
FC-13 & 715 & 179 & 357 & 107 & 300 & 4 \\
FC-14 & 635 & 318 & 286 & 95 & 350 & 0 \\
FC-15 & 749 & 562 & 300 & 112 & 200 & 11 \\
FC-16 & 674 & 674 & 236 & 101 & 250 & 7 \\
\hline
\end{tabular}

immediately to the base mix and mixed for a duration until there was no physical sign of the foam on the surface and all the foam is uniformly distributed and incorporated into the mix.

After the mixing procedure is completed, from each concrete mix, six $50 \mathrm{~mm}$ cube samples are cast for $3,7,28$, 90 , and 180 days. The specimens are demolded $24 \mathrm{~h}$ after the casting and placed in water tank at $23 \pm 2^{\circ} \mathrm{C}$. A compressive test was carried out at the given ages using a ELE International Compression Testing Machine. The fracture pieces of the cubes after conducting the compression test were preserved for $w_{n}$ tests.

The loss on ignition method was used to determine the $w_{n}$ content at all selected ages of hydration. Small pieces from the samples (approximately 1-2 $\mathrm{mm}$ in size) cured in saturated limewater were pulverized and soaked in acetone to stop further hydration. The pulverized samples were heated in an oven at $105^{\circ} \mathrm{C}$ for $24 \mathrm{~h}$, followed by heating in a muffle furnace at $1050^{\circ} \mathrm{C}$ for $3 \mathrm{~h}$. The $w_{n}$ was obtained as the difference in mass between the sample heated at $105^{\circ} \mathrm{C}$ and $1050^{\circ} \mathrm{C}$ normalized by the mass after heating to $1050^{\circ} \mathrm{C}$ and making up for the loss on ignition of unhydrated FC (or of the unhydrated FC and the CRM multiplied by their respective mass fractions).

2.4. Determination of Nonevaporable Water. The hardening process in concrete is caused by chemical reaction taking place in the cement part of the mixture. The cumulative of these reactions is highly related to the nonevaporable water $\left(w_{n}\right)$ content in the reaction product and determines hardened properties of the concrete mixture.

Chemically bound water or $w_{n}$ was decided to calculate the degree of hydration. For FC pastes, the degree of 
hydration can be determined based on that; the hydration of $1 \mathrm{~g}$ of anhydrous cement produces $0.25 \mathrm{~g}$ of $w_{n}$ [20]. All the calculations described in this subsection and the following subsections were carried out on the ignited basis (i.e., $1 \mathrm{~g}$ of sample was ignited at $1050^{\circ} \mathrm{C}$ in an electric furnace for $3 \mathrm{~h}$ ). The loss on ignition (LOI) of the as received sample was calculated by

$$
L_{c}=\sum_{i=1}^{6} L_{c, i}=\sum_{i=1}^{6} \frac{m_{c, 105, i}-m_{c, 1050, i}}{m_{c, 105, i}}
$$

where

$$
\begin{aligned}
& L_{c}=\text { average LOI of sample, } \\
& L_{c, i}=\text { LOI of the } i \text { th sample, } \\
& m_{c, 105, i}=\text { mass of the } i \text { th sample after oven drying, } \\
& m_{c, 1050, i}=\text { mass of the } i \text { th sample after furnace } \\
& \text { ignition. }
\end{aligned}
$$

The $W_{n}$ content of hydrated pastes on the ignited basis was calculated by

$$
\begin{aligned}
\frac{w_{n}}{c}= & \left(\frac{m_{105}}{m_{1050}}\right) \\
& \times\left[\left(\frac{p}{c}\right)\left(1-L_{p}\right)+\left(\frac{f}{c}\right)\left(1-L_{f}\right)+\left(1-L_{c}\right)\right] \\
& -\left(\frac{p}{c}\right)-\left(\frac{f}{c}\right)-1,
\end{aligned}
$$

where

$$
\begin{aligned}
& w_{n}=\text { nonevaporable water content, } \\
& p=\text { initial MIRHA pozzolan, } \\
& f=\text { initial fine aggregate, } \\
& c=\text { initial cement content, } \\
& L_{p}=\text { LOI of MIRHA pozzolan, } \\
& L_{f}=\text { LOI of fine aggregate, } \\
& L_{c}=\text { LOI of cement. }
\end{aligned}
$$

\section{Result, Analysis, and Discussion}

3.1. Compressive Strength. Compressive strength was determined at the age of $3,7,28,90$, and 180 days. Table 5 presents the compressive strength results in $\mathrm{N} / \mathrm{mm}^{2}$ of the 16 trial mixture proportions. The results show that 3-, 7-, 28-, 90-, and 180-day strengths were obtained in the range of 1.2-6.9, 2.3$12.6,5.5-28.1,13.9-47.3$, and $12-57.9 \mathrm{~N} / \mathrm{mm}^{2}$, respectively.

The highest and the lowest compressive strength were obtained from FC-4 and FC-10, respectively. The summary of main effect plot for 3 to 180 days of compressive strength of FC is shown in Figure 3.

Figure 2 is the main effect plot for compressive strength at $3,7,28,90$, and 180 days using orthogonal-array procedure. The development of compressive strength of foamed concrete is illustrated in Figure 3.
TABLE 5: Test results of compressive strength for MIRHA FC.

\begin{tabular}{lccccc}
\hline \multirow{2}{*}{ Code } & \multicolumn{5}{c}{ Compressive strength $\left(\mathrm{N} / \mathrm{mm}^{2}\right)$} \\
& $3 \mathrm{~d}$ & $7 \mathrm{~d}$ & $28 \mathrm{~d}$ & $90 \mathrm{~d}$ & $180 \mathrm{~d}$ \\
\hline FC-1 & 3.2 & 8.3 & 17.1 & 27.7 & 34.7 \\
FC-2 & 6.4 & 12.2 & 26.8 & 43.6 & 52.2 \\
FC-3 & 3.1 & 5.9 & 13.4 & 31.1 & 27.5 \\
FC-4 & 1.2 & 2.3 & 5.5 & 13.9 & 12.0 \\
FC-5 & 4.2 & 7.5 & 17.4 & 27.8 & 36.7 \\
FC-6 & 4.6 & 11.0 & 20.3 & 33.8 & 42.4 \\
FC-7 & 4.1 & 7.2 & 17.3 & 26.3 & 34.4 \\
FC-8 & 5.8 & 12.2 & 24.8 & 39.0 & 51.1 \\
FC-9 & 6.0 & 11.2 & 25.5 & 44.2 & 55.8 \\
FC-10 & 6.9 & 12.6 & 28.1 & 47.3 & 57.9 \\
FC-11 & 3.1 & 7.4 & 14.5 & 25.6 & 33.0 \\
FC-12 & 4.5 & 8.3 & 19.1 & 37.9 & 42.6 \\
FC-13 & 3.0 & 5.8 & 13.2 & 21.3 & 26.5 \\
FC-14 & 4.0 & 7.6 & 16.8 & 26.6 & 31.9 \\
FC-15 & 5.1 & 9.7 & 21.4 & 34.7 & 41.8 \\
FC-16 & 3.6 & 9.2 & 17.3 & 32.5 & 35.5 \\
\hline
\end{tabular}

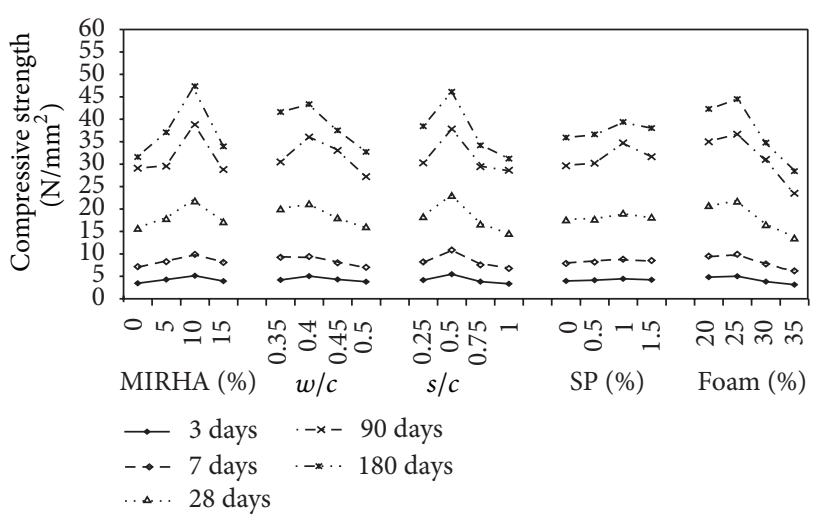

FIGURE 2: Summary of main effect plot for compressive strength.

Generally, normal FC had lower compressive strength than the MIRHA-FC. At the early ages (3 days of age), control MIRHA-FC samples had superior compressive strength than the normal FC. It was due to the fact that the pozzolanicity of MIRHA started almost immediately when mixed with the concrete. Additionally, the increasing percentage of MIRHA in the concrete directly led to the declining percentage of portland cement used in the proportion. This reduced the production of $\mathrm{Ca}(\mathrm{OH})_{2}$ and slowed down the reaction with $\mathrm{SiO}_{2}$ presented in MIRHA. On the other hand, pozzolanic material supported in achieving more consistent distribution of air voids by providing uniform outside layer on each bubble and thereby prevented merging of bubbles. In addition, the replacement level 5-10\% MIRHA was found optimum to contribute void distribution maximally and facilitate the strength. However, the trend of 5-10\% level was different with $15 \%$ level. The $15 \%$ level showed the decrease in the strength due to the excessive water absorption. The character of its 


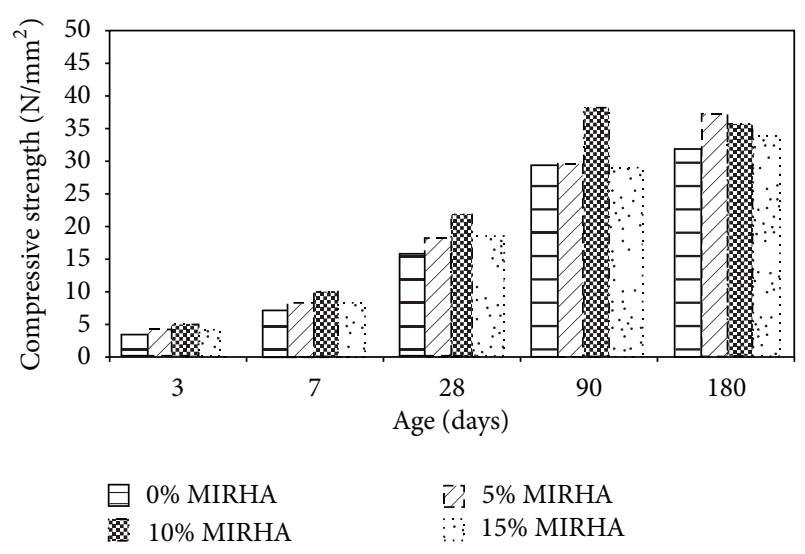

FIGURE 3: The compressive strength development of foamed concrete.

TABLE 6: Nonevaporable water content $\left(w_{n}\right)$ by OD/FI.

\begin{tabular}{lccccc}
\hline \multirow{2}{*}{ MIRHA (\%) } & \multicolumn{5}{c}{$w_{n / c}(\mathrm{~g} / \mathrm{g}$ initial cement) } \\
& 3 & 7 & 28 & 90 & 180 \\
\hline 0 & 0.101 & 0.116 & 0.131 & 0.147 & 0.153 \\
5 & 0.1 & 0.115 & 0.129 & 0.145 & 0.15 \\
10 & 0.096 & 0.111 & 0.126 & 0.14 & 0.145 \\
15 & 0.089 & 0.102 & 0.116 & 0.129 & 0.134 \\
\hline
\end{tabular}

pore structure in MIRHA led to excessive water absorption and yielded disordered foam distribution. This decreased the strength of the concrete.

At the age of 28 days, the average normal strength of FC without MIRHA was found to be $92.3 \%$ of the required strength for structural lightweight concrete, which is $17 \mathrm{MPa}$. On the other hand, the FC concrete mixes containing $5 \%$ and $15 \%$ MIRHA achieved $113.8 \%$ and $109.3 \%$ of the strength of normal FC. However, the $10 \%$ MIRHA enhanced the strength above the normal FC by $138.9 \%$. Even at the age of 90 days, the compressive strength of $10 \%$ MIRHA mixes was about $33.3 \%$ higher than the strength of normal FC. Beyond 90 days, the compressive strength of 10\% MIRHA was increased up to $49.9 \%$ at the age of 180 days.

3.2. Nonevaporable Water. Nonevaporable water content $\left(w_{n}\right)$ can be used to determine the degree of hydration. For normal FC with MIRHA, determining the degree of hydration using chemically bond water is complicated because it is difficult to separate the water associated with the reaction of the MIRHA in the hydrated cement. A previous study [21] showed that the effect of cement replacement material on the nonevaporable water per unit mass of binder was lower at all ages. It is due to the presence of lower cement content that the pozzolanic reaction of the CRM typically does not bind as much water as hydrated cement. However, an assumption that the CRM does not either react or contribute to chemically bound water is not totally true. Results of $w_{n}$ obtained from oven dry/furnace ignition (OD/FI) are shown in Table 6.
Reduction of $w_{n}$ due to the addition of MIRHA on FC can be explained as follows.

(a) It was due to the fact that the increasing percentage of MIRHA in the FC mixes directly led to declining percentage of OPC used in the proportion. To reduce amount of cement will cause the quantity of chemical water bound as $w_{n}$ is reduced as well.

(b) MIRHA participates in three main reactions: (i) with unhydrated $\mathrm{C}_{3} \mathrm{~S}$ and water to form one type of C-S-H; (ii) with the $\mathrm{CH}$ to form a different C-S$\mathrm{H}$; and (iii) with existing C-S-H to yield a further modified hydrate. In incorporating the same quantity of $\mathrm{C}_{3} \mathrm{~S}$, adding MIRHA in system combines less water per gram of cement than does that for $\mathrm{C}_{3} \mathrm{~S}$ alone. Therefore, MIRHA serves to lower the amount of bound water in the system.

(c) MIRHA particles also serve to adsorb water, thus making the water unavailable for cement hydration. This adsorption thus increases the amount of evaporable water. In addition, the pozzolanic C-S-H is not only a different type of C-SH than that from cement hydration, but one that also adsorbs more water, thus decreasing the available hydration water further. Thus, MIRHA FC has lower $w_{n}$ than normal FC.

From aforementioned discussion, it can be concluded that pozzolanic reaction of MIRHA alters the system hydration process, yielding lower nonevaporable water content FC.

3.3. Change in Nonevaporable Water Content due to the Presence of a Cement Replacement Material [21]. In this section, a simple model developed by Schwarz and Neithalath [21] to acquire the change in $w_{n}$ content due to the incorporation of MIRHA or filler is detailed, and this information will be used to extract the total degrees of hydration of the FC incorporating MIRHA or replacement material can be showed as

$$
\left(w_{n}\right)_{T}=\left(w_{n}\right)_{c} m_{c}+\left(w_{n}\right)_{r} m_{r}
$$

where $\left(w_{n}\right)_{c}$ and $\left(w_{n}\right)_{r}$ are the nonevaporable water contents of the cement and replacement material, respectively, and $m_{c}$ and $m_{r}$, are their mass fraction. If the replacement material is purely a filler, then $\left(w_{n}\right)_{r}=0$. A cement replacement material in a paste system might make possible an enhancement in the hydration of the available cement grains in addition to its own hydration. According to a case, the nonevaporable water content of the cement can be explained as

$$
\left(w_{n}\right)_{c}=\left(w_{n}\right)_{c-0}+\left(w_{n}\right)_{c-r},
$$

where $\left(w_{n}\right)_{c-0}$ is the nonevaporable water content of a cement paste with no CRM and $\left(w_{n}\right)_{c-r}$ is the nonevaporable water content as a result of the improvement in cement hydration due to the presence of the replacement material. If the equation $\left(w_{n}\right)_{c}=\left(w_{n}\right)_{c-0}$, when there is no replacement 
TABLE 7: $\Delta w_{n / c}$ due to the presence of MIRHA by OD/FI.

\begin{tabular}{lccccc}
\hline \multirow{2}{*}{ MIRHA (\%) } & \multicolumn{5}{c}{$\Delta\left(w_{n / c}\right) r(\mathrm{~g} / \mathrm{g}$ initial cement) } \\
& 3 & 7 & 28 & 90 & 180 \\
\hline 5 & 0.0039 & 0.0046 & 0.0046 & 0.0054 & 0.0052 \\
10 & 0.0048 & 0.0050 & 0.0058 & 0.0077 & 0.0078 \\
15 & 0.0027 & 0.0030 & 0.0040 & 0.0035 & 0.0040 \\
\hline
\end{tabular}

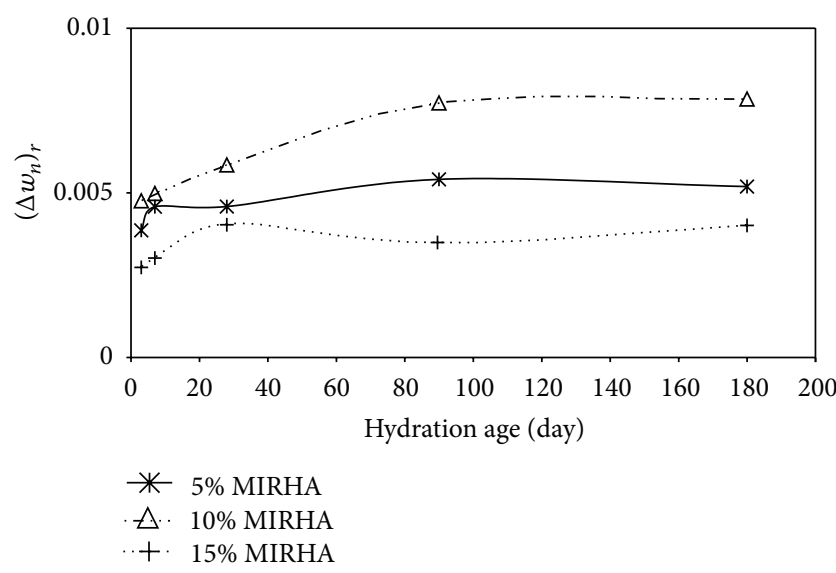

FIGURE 4: $\Delta w_{n / c}$ due to the presence of MIRHA using OD/FI technique.

material present in the system. Substitution of (4) into (3) can be stated as

$$
\left(w_{n}\right)_{T}=\left[\left(w_{n}\right)_{c-0}+\left(w_{n}\right)_{c-r}\right] m_{c}+\left(w_{n}\right)_{r} \cdot m_{r}
$$

The above equation can be restated as

$$
\left(w_{n}\right)_{T}-\left(w_{n}\right)_{c-0} m_{c}=\left(w_{n}\right)_{c-r} m_{c}+\left(w_{n}\right)_{r} m_{r}
$$

The right hand side of (4) gives a term for the change in nonevaporable water content in a modified paste $\left(\Delta w_{n}\right)_{r}$ as a result of the hydration of the cement replacement material and the enhancement in hydration of the cement grains resulting from the presence of the replacement material. Consider

$$
\left(\Delta w_{n}\right)_{r}=\left(w_{n}\right)_{c-r} m_{c}+\left(w_{n}\right)_{r} m_{r}
$$

$\left(\Delta w_{n}\right)_{r}$ provides an indication of the combined effects of enhancement in cement hydration due to increased effective $w / c$ in a paste modified with a filler and the secondary hydration in a paste modified with a pozzolanic material. Since all the terms in the left hand side of (6) are known, determination of $\left(\Delta w_{n}\right)_{r}$ is straightforward. For a plain paste, $\left(\Delta w_{n}\right)_{r}$ will always be zero. It should be noted here that $\left(\Delta w_{n}\right)_{r}$ does not separate the individual effects of enhancement in hydration and secondary reaction.

Table 7 shows the change in nonevaporable water contents due to the presence of MIRHA (as expressed $\Delta w_{n / c}$ ) that is calculated by (7). A closer look at the data in Figure 4 also shows that, for all the ages, the $w_{n}$ of MIRHA FC are higher than the $w_{n}$ of the normal FC multiplied by the mass fraction of cement $\left(m_{c}\right)$ in the MIRHA FC. For instance, the $w_{n} 10 \%$ MIRHA FC at 180 days is 0.145 , which is greater than $0.9 *$ 0.153 , where 0.153 is the $w_{n}$ of normal FC. This shows that MIRHA contributes to $w_{n}$ by facilitating an improvement in the hydration of available cement grains and/or through its own pozzolanic reaction.

Figure 4 shows the values of $\Delta\left(w_{n / c}\right)_{r}$ plotted against hydration age for the MIRHA FC by OD/FI. Until about 28 days, the $\Delta\left(w_{n / c}\right)_{r}$ values of the FC with MIRHA powder increased, indicating increased hydration of the cement grains because of the higher effective $w / c$. Beyond 28 days, $15 \%$ MIRHA $\Delta\left(w_{n / c}\right)_{r}$ is seen to decrease, showing that the secondary reaction of the replacement material is not compensating for the dilution effect. However, for the FC incorporating with $5 \%$ and $10 \%$ MIRHA powder, $\left(\Delta w_{n}\right)_{r}$ increases consistently with time. This shows that a $5-10 \%$ replacement of cement with MIRHA powder has higher value for change in nonevaporable water can be considered to be effective.

3.4. Degree of Hydration. Calculating degree of hydration $(\mathrm{DoH})$ is one of the primary reasons for measuring nonevaporable water contents in cement-based mixtures. This section will consider degree of hydration based on the FC mixture data from all sixteen experiments from orthogonalarray experiment, thus synthesizing the experimental work. Many researchers convert nonevaporable water measurements directly to degree of hydration values using the relationship

$$
\begin{gathered}
\alpha=\frac{\left(w_{n}\right)_{c}}{\left(w_{n}\right)_{c-\infty}} \\
\alpha_{T}=\frac{\left(w_{n}\right)_{T}}{\left(w_{n}\right)_{c-\infty}}-\left(w_{n}\right)_{r} m_{r}\left[\frac{1}{\left(w_{n}\right)_{r-\infty}}-\frac{1}{\left(w_{n}\right)_{c-\infty}}\right] .
\end{gathered}
$$

On the assumption, that nonevaporable water content is a reasonable estimate for the amount of chemically bound water. (Note that $k$ is the mass of chemically combined water required to fully hydrate one gram of cement and is thus cement-specific. In this work, $\left(w_{n}\right)_{c-\infty}=0.2386$ ).

Figure 5 shows a plot of degree of hydration over time, where the degrees of hydration values have been calculated with (8) for normal FC and (9) for MIRHA as cement replacement that was adopted in Neithalath's study [17]. Since the ultimate nonevaporable water contents $\left(w_{n}\right)_{r-\infty}$ of MIRHA are much lower compared to that of the cement (in this work, $\left.\left(w_{n}\right)_{r-\infty}=0.05\right)$.

Further insight into this behavior can be obtained by using degree of hydration value to predict MIRHA FC properties, such as compressive strength, and comparing these predicted values with measured ones.

The correlation between total degree of hydration and time can be adequately expressed using a modified threeparameter hyperbolic expression of the form

$$
\alpha_{T}=a_{1}\left[1-\frac{1}{\left(1+a_{2} t\right)^{1 / a_{3}}}\right],
$$




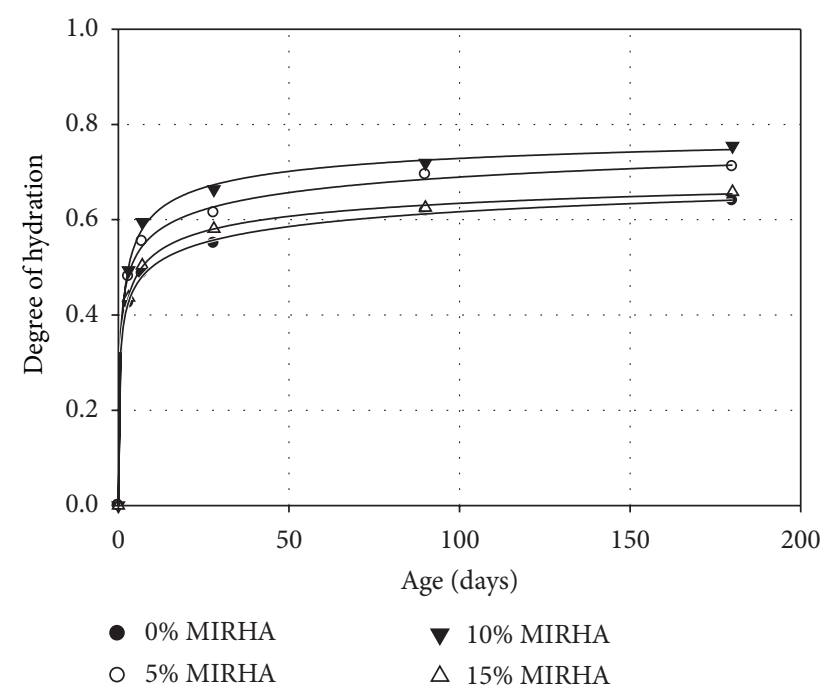

FIGURE 5: Degree of hydration of FC from $w_{n}$ measured by OD/FI.

TABLE 8: $a_{1}, a_{2}$, and $a_{3}$ are fitting parameters for degree of hydration of FC.

\begin{tabular}{lccc}
\hline MIRHA (\%) & $a_{1}$ & $a_{2}$ & $a_{3}$ \\
\hline 0 & 0.83 & 4.67 & 2.94 \\
5 & 0.99 & 29.71 & 6.67 \\
10 & 0.79 & 9.87 & 4.21 \\
15 & 0.95 & 34.17 & 7.80 \\
\hline
\end{tabular}

TABLE 9: $a_{1}, a_{2}$, and $a_{3}$ are fitting parameters for degree of hydration of VCAS and SF (Neithalath's study [17]).

\begin{tabular}{lccccccc}
\hline $\begin{array}{l}\text { VCAS } \\
\text { content (\%) }\end{array}$ & $a_{1}$ & $a_{2}$ & $a_{3}$ & SF content (\%) & $a_{1}$ & $a_{2}$ & $a_{3}$ \\
\hline 0 & 0.81 & 7.22 & 2.74 & 0 & 0.81 & 7.22 & 2.74 \\
6 & 1.33 & 31.10 & 8.98 & 6 & 0.78 & 3.82 & 2.32 \\
9 & 3.85 & 89.69 & 38.46 & 9 & 0.74 & 2.22 & 1.87 \\
15 & 1.07 & 11.53 & 5.44 & & & & \\
\hline
\end{tabular}

where $a_{1}, a_{2}$, and $a_{3}$ are fitting parameters that are shown in Table 8; the values are shown in respective figures. The continuous lines in Figure 5 represent the fits of (10) to calculate total degrees of hydration. The total degrees of hydration of normal and MIRHA FC were predicted by this equation with an $R^{2}$ value greater than 0.98 in all mixes. This model is compared with previous study [17] that investigated vitreous calcium aluminosilicate (VCAS) and silica fume $(\mathrm{SF})$ as supplementary cement material in high-performance cementitious, which is listed in Table 9.

\section{Conclusion}

Increasing amounts of MIRHA in the FC led to reduction in nonevaporable water contents $\left(w_{n}\right)$ as compared to the normal FC. The MIRHA FC mixes were found to use less water for hydration as compared to normal FC. The hydrate water content that indicated the chemically bound water in the C-S-H phase was highest for the MIRHA FC over at 3 days of hydration, while the normal FC showed the lowest value. At later ages, the nonevaporable water content in the MIRHA leveled off, achieving an ultimate value about $12 \%$ less than that of the normal FC.

The optimum FC properties were achieved at $10 \%$ MIRHA composition as proven from highest compressive strength. This level corresponds to the highest values in change in nonevaporable water and degree of hydration.

\section{Conflict of Interests}

The authors declare that there is no conflict of interests regarding the publication of this paper.

\section{References}

[1] C. L. Hwang and S. Chandra, "The use riche husk in concrete," in Waste Materials Used in Concrete Manufacturing, S. Chandra, Ed., William Andrew, 1997.

[2] International-Rice-Research-Institute, "Table 1. Paddy rice production (000 t), by country and geographical region, 1961-2012. (FAO)," 2012.

[3] N. L. M. Kamal, M. F. Nuruddin, and N. Shafiq, "The influence of burning temperatures and percentage inclusion of microwave incinerated rice husk ash (MIRHA) on normal strength concrete," in Proceedings of the International Conference on Construction and Building Technology (ICCBT '08), UTP, Kuala Lumpur, Malaysia, 2008.

[4] K. Andre and M. F. Nuruddin, "The effect of microwave incinerated rice husk ash (MIRHA) on concrete properties," 2007.

[5] A. A. Elhsameed, N. Shafiq, and M. F. Nuruddin, "Effect of microwave incinerated rice husk ash (MIRHA) on workability and compressive strength of concrete," Advanced Materials Research, vol. 935, 2014.

[6] N. L. M. Kamal, "The influence of microwave-incinerated rice husk ash (Mirha) on interfacial zone characteristic and concrete properties," in Civil Engineering, Master Bandar Sri Iskandar: Universiti Teknologi Petronas, 2010.

[7] A. El-Dakroury and M. S. Gasser, "Rice husk ash (RHA) as cement admixture for immobilization of liquid radioactive waste at different temperatures," Journal of Nuclear Materials, vol. 381, no. 3, pp. 271-277, 2008.

[8] R. Bayuaji and M. F. Nuruddin, "Optimum mix proportioning of foamed concrete using taguchi method," in Proceedings of the UTP Internal PG Symposium, Universiti Teknologi PETRONAS, 2009.

[9] M. R. Jones and A. McCarthy, "Behaviour and assessment of foamed concrete for construction applications," in Proceedings of the International Conference on the Use of Foamed Concrete in Construction, pp. 61-88, July 2005.

[10] H. Y. Lee, "Exploitation of solid wastes in foamed concrete challenges a head," in Use Foamed Concrete in Construction, R. K. Dhir, Ed., pp. 15-27, Thomas Telford, London, UK, 2005.

[11] A. C. M. Liew, "New innovative lightweight foam concrete technology," in Proceedings of the International Conference on the Use of Foamed Concrete in Construction, pp. 45-50, July 2005.

[12] P. Domone and J. M. Illston, Construction Materials: Their Nature and Behaviour, Taylor \& Francis, 2001. 
[13] M. R. Jones and A. McCarthy, "Preliminary views on the potential of foamed concrete as a structural material," Magazine of Concrete Research, vol. 57, no. 1, pp. 21-31, 2005.

[14] A. M. MR Jones, "Behaviour and assessment of foamed concrete construction applications," in Use of Foamed Concrete in Construction, pp. 62-88, University of Dundee, 2005.

[15] C. T. L. Tam, T. Y. Lim, R. Sri Ravindrarajah, and S. L. Lee, "Relationship between strength and volumetric composition of moist-cured cellular concrete," Magazine of Concrete Research, vol. 39, no. 138, pp. 12-18, 1987.

[16] M. F. Nuruddin and R. Bayuaji, "Application of Taguchis approach in the optimization of mix proportion for microwave incinerated rice husk ash foamed concrete," International Journal of Civil \& Environmental Engineering, vol. 9, pp. 121-129, 2009.

[17] N. Neithalath, J. Persun, and A. Hossain, "Hydration in highperformance cementitious systems containing vitreous calcium aluminosilicate or silica fume," Cement and Concrete Research, vol. 39, no. 6, pp. 473-481, 2009.

[18] R. Roy, "A primer on the Taguchi method," 1990.

[19] J. Antony, D. Perry, C. Wang, and M. Kumar, "An application of Taguchi method of experimental design for new product design and development process," Assembly Automation, vol. 26, no. 1, pp. 18-24, 2006.

[20] R. C. A. Pinto, S. V. Hobbs, and K. C. Hover, "Relationship between nonevaporable water content and hardened properties of high performance mixtures," ACI Special Publication, vol. 189, pp. 351-366, 2000.

[21] N. Schwarz and N. Neithalath, "Influence of a fine glass powder on cement hydration: comparison to fly ash and modeling the degree of hydration," Cement and Concrete Research, vol. 38, no. 4, pp. 429-436, 2008. 

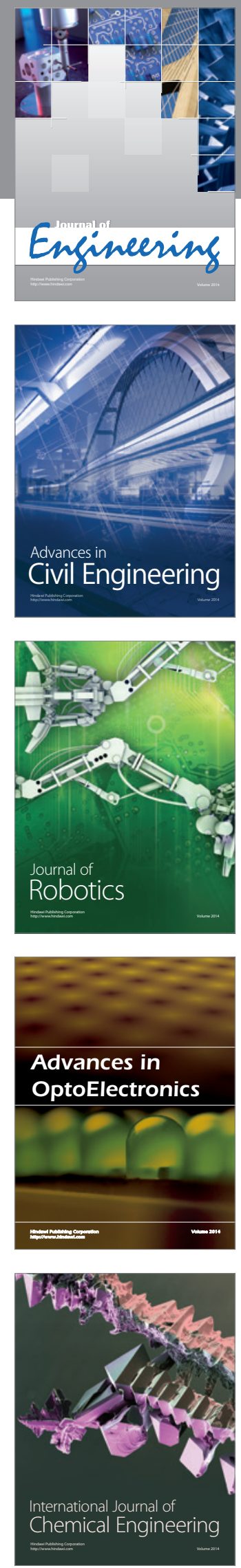

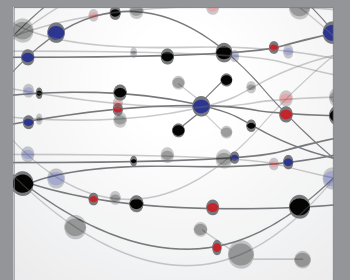

The Scientific World Journal
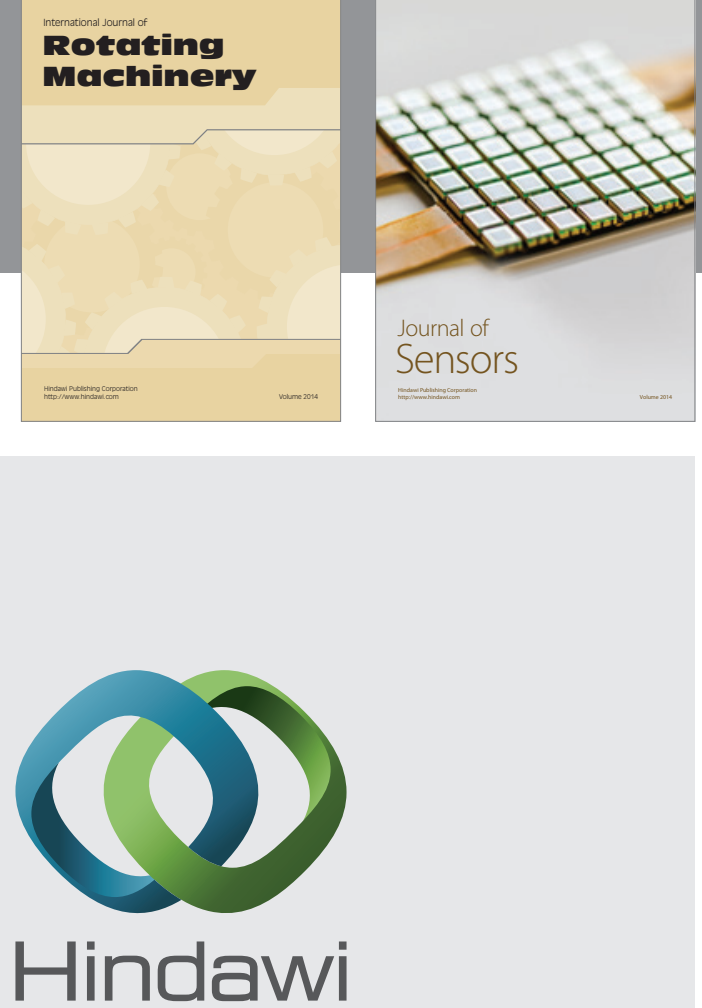

Submit your manuscripts at http://www.hindawi.com
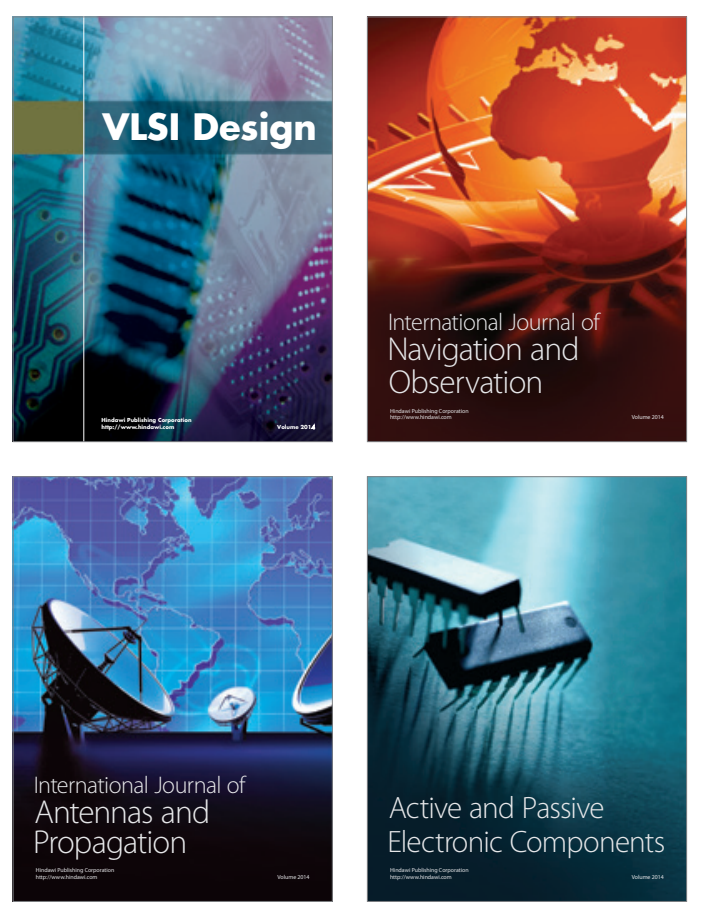
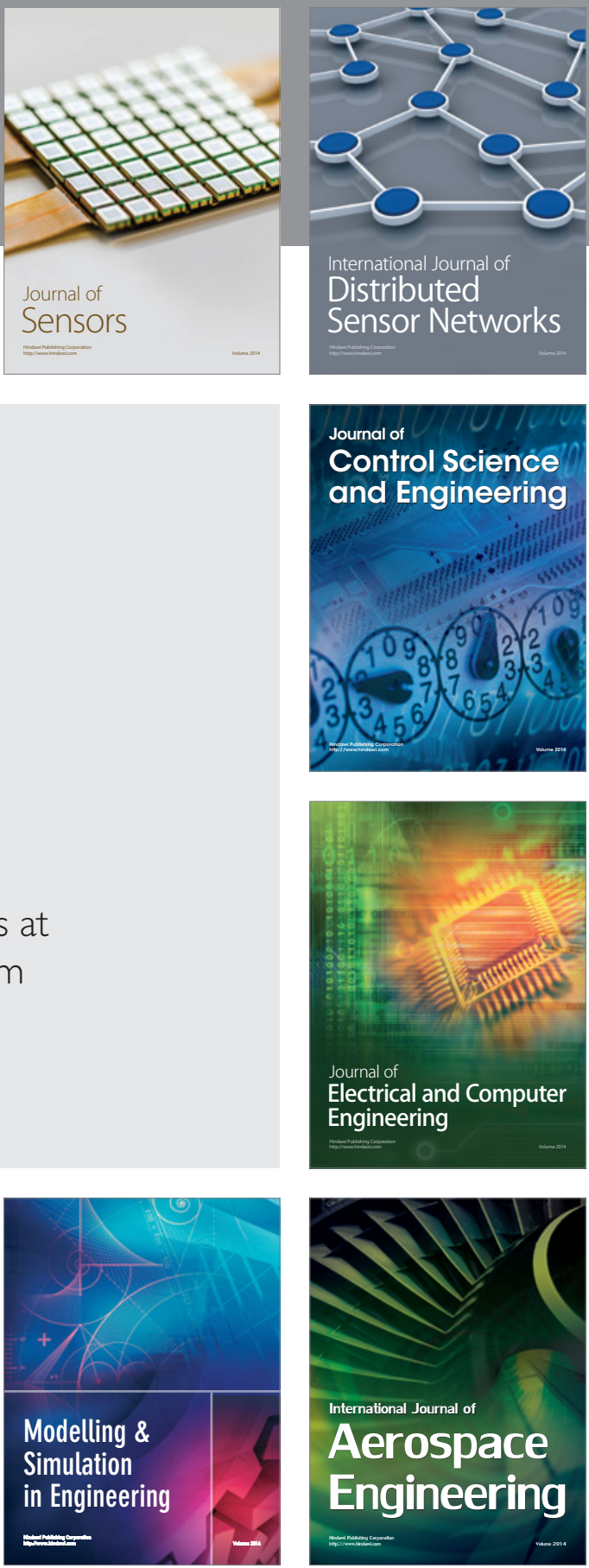

Journal of

Control Science

and Engineering
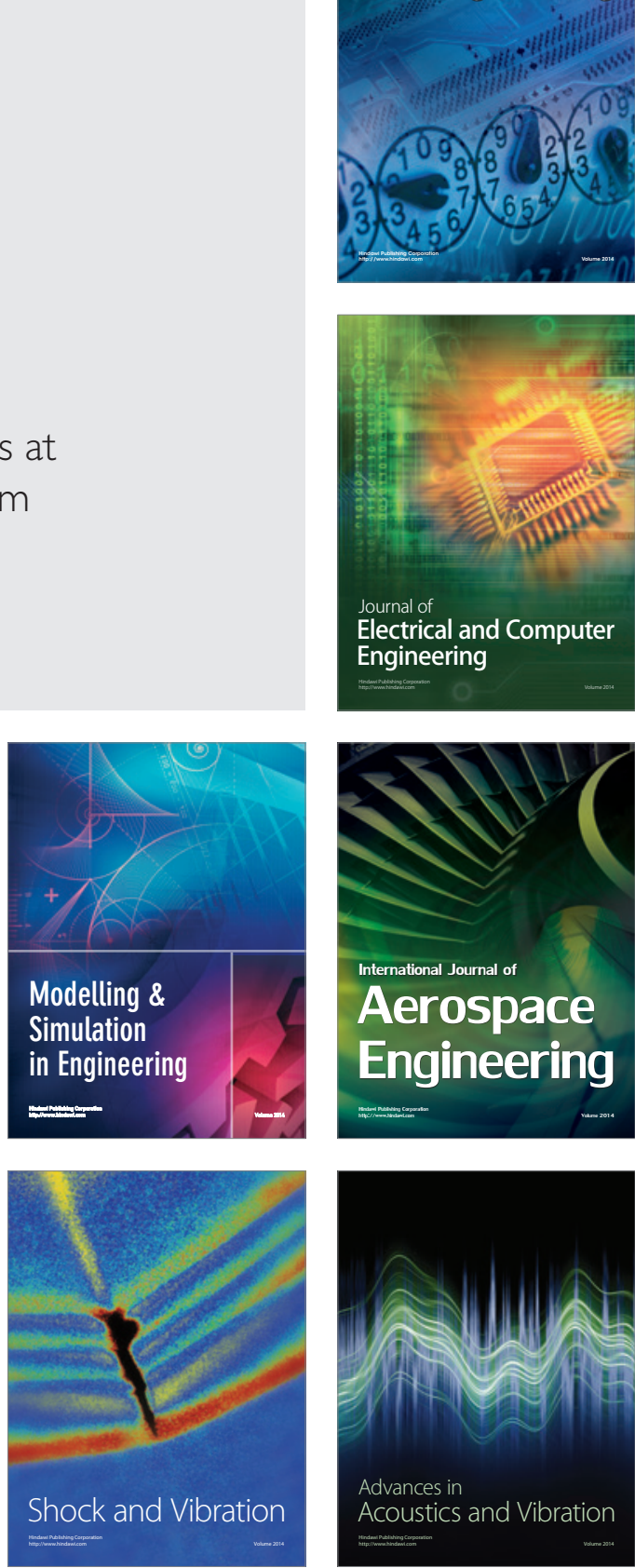